\title{
DECIFRA-ME OU TE DEVORO: DESAFIOS NO USO DE TECNOLOGIAS PARA PRESERVAÇÃO E ACESSO EM ARQUIVOS
}

\author{
DECIPHER ME OR I WILL DEVOUR YOU - CHALLENGES IN THE USE OF \\ TECHNOLOGIES FOR PRESERVATION AND ACCESS IN ARCHIVES
}

Sérgio Conde de Albite Silva Arquivista-conservador, mestre em Memória Social e doutor em Ciência da Informação; professor do Departamento de Estudos e Processos Arquivísticos da Universidade Federal do Estado do Rio de Janeiro - UNIRIO e do Programa de Pós-Graduação em Ciência de Informação da Universidade Federal Fluminense - UFF. albite@uninet.com.br

\begin{abstract}
Resumo
Analisa o uso da microfilmagem e da digitalização para a preservação e acesso de documentos em arquivos. Apresenta como algumas instituições internacionais na área estão lidando com a questão. A opção por uma ou outra tecnologia para a preservação e acesso deve se basear em dados estatísticos e estudos retrospectivos obtidos nas experiências desenvolvidas. Conhecer e medir, quantitativa e qualitativamente, os recursos humanos, tecnológicos e financeiros que foram aplicados em microfilmagem e digitalização de acervos para a preservação e acesso nas instituições arquivísticas, principalmente as públicas, oferece uma base para projetos futuros.
\end{abstract}

Palavras-chave: microfilmagem. Digitalização. Preservação. Acesso. Arquivos.

\section{INTRODUÇÃO}

Este artigo retoma e trata de ampliar a questão do uso da microfilmagem e da digitalização para a preservação e acesso de documentos arquivísticos. Para isso, apresenta a forma como algumas instituições de referência internacional na área estão lidando com a questão e aponta novos aspectos e elementos tidos como diferenciais para a equação do problema.

Entende-se que a identificação, levantamento e análise, de modo sistemático e metodológico, da aplicação, dos efeitos, da relação custo X benefício e da utilização da microfilmagem e da digitalização nos arquivos nos últimos anos deve subsidiar as decisões e escolhas a serem feitas a curto, médio e longo prazo. Isto é, conhecer e medir, quantitativa e qualitativamente, os recursos humanos, tecnológicos e financeiros já aplicados na microfilmagem e na digitalização de acervos para a preservação e acesso nas instituições arquivísticas, principalmente, as públicas, é a base para projetos futuros.

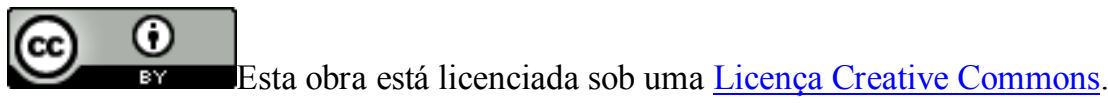

DOI 10.5007/1518-2924.2011v16nesp1p40 
Especificamente, no caso brasileiro, desconhece-se a existência de qualquer estudo nos termos acima referidos, apesar dos mais de trinta anos de uso da microfilmagem e de, no mínimo, dez anos de digitalização para a preservação e/ou acesso de documentos. O fato ganha relevância quando se observa que o uso dessas tecnologias no Brasil tem sido financiado, quase que exclusivamente, com dinheiro público.

Assim, o pressuposto que norteia esse trabalho é o de que as decisões políticas, as escolhas tecnológicas e os investimentos orçamentários em relação ao uso da microfilmagem e/ou da digitalização para preservação e acesso carecem de estudos sobre o uso dessas tecnologias, os óbices enfrentados e os resultados obtidos. Tanto as escolhas e decisões do passado (microfilmagem), como as escolhas e decisões de hoje (microfilmagem e/ou digitalização) foram e continuam sendo tomadas sem dados confiáveis sobre a quantidade e qualidade do que foi produzido, sobre as condições de uso e preservação dos produtos gerados e sem o conhecimento da relação custo $\mathrm{X}$ benefício das mídias resultantes (quantos microfilmes, CDs, bases de dados foram produzidos? qual o estado de conservação desses produtos? qual a sua média mensal ou anual de consultas? qual o grau de satisfação dos usuários?). Sem tais estudos retrospectivos, as decisões políticas, tecnológicas e orçamentárias tomadas para a preservação e acesso dos acervos nas instituições públicas brasileiras tendem a tornar mais frágeis tanto os acervos como as próprias instituições de custódia.

Em suma, ao se associar conhecimento a fatos, ou seja, relacionar a frequência de eventos às rubricas e valores orçamentários empenhados, bem como as decisões políticas às escolhas tecnológicas, aumenta-se a possibilidade de (re)conhecer o tênue limite entre ousadia e responsabilidade daqueles que decidem e propõem novos projetos.

\section{TECNOLOGIA COMO ARTEFATO HISTÓRICO}

A origem da palavra tecnologia é datada do século VI a.C. e surge na Grécia pela junção dos vocábulos thekné (arte) e logos (conhecimento), quando era usada principalmente para se referir à retórica e à gramática. Nascida das experimentações empíricas do homem, a tecnologia aproxima-se, mais tarde, da ciência sistematizada, com quem estabelece uma via de mão dupla, apresentando-se como parte e resultado da investigação científica. O conceito de tecnologia tem aparecido vinculado ao desenvolvimento do capitalismo, à revolução industrial e à organização do trabalho. 
Considerando tecnologia como um rol de conhecimentos e procedimentos construídos pelo homem ao longo da história da civilização, inicialmente de forma empírica, nas tentativas de dominar e tirar proveito dos recursos naturais, o fogo é parte dos primeiros momentos do homem descobridor e aplicador de tecnologias. Nessa primeira fase, a história da tecnologia pode ser associada à luta pela obtenção de fontes para a subsistência, onde o fogo é fundamental para a preparação dos alimentos, principalmente o peixe e outros produtos da água, bem como raízes e tubérculos, o que libera o homem em relação ao clima e ao lugar fixo para habitar (ENGELS, 1975, p. 22).

O desenvolvimento de armas, a domesticação e criação de animais, o cultivo de plantas, a irrigação e o "arado de ferro puxado por animais, que torna possível lavrar a terra em grande escala", ou seja, a agricultura, são elementos de tecnologia importantes no surgimento da civilização (ENGELS, 1975, p. 27). A agricultura, surgida no Egito e na Mesopotâmia, pode ser considerada um grande salto, pois é dessa forma que o homem encontra um meio quase ilimitado para sua subsistência.

A roda, a adubagem, os excedentes na produção dos alimentos, os instrumentos de ferro, o cobre e o bronze, os moinhos a olaria, o azeite e o vinho, as carretas e carros de guerra, os barcos, a escrita, os números, a astronomia, o comércio, a pilhagem, a metalurgia, a arquitetura, os primeiros núcleos urbanos, a imprensa, a indústria e a arte compõem o conjunto de tecnologias e aquilo que Engels (1975, p. 177) chama de período de civilização.

No final do século XVI, Galileu constrói seus instrumentos de pesquisa e trabalho baseado nos conhecimentos práticos das oficinas e artesãos. A máquina a vapor surge no início do século XVIII como resultado de trabalho e da investigação prática de um ferreiro e de um mecânico. Os caminhos se entrecruzam e sofrem influências recíprocas entre a produção científica de base, a ciência aplicada, as invenções e as tecnologias. É a chamada era das invenções nos séculos XVIII e XIX. A eletricidade e sua aplicação prática e comercial é um bom exemplo dessa época. Surge o telégrafo, o rádio. Sofisticam-se os motores, e o petróleo surge como energia central e, logo a seguir, a petroquímica e os plásticos. $\mathrm{O}$ mundo dos eletrodomésticos começa; surge a televisão, a eletrônica e a energia nuclear, os computadores e a robótica. São os anos finais do século XX.

Não é possível dissociar a história da civilização e a tecnologia. A tecnologia, como artefato histórico, acompanha, antecipa, regula, desenvolve e sofistica as forças produtivas, 
econômicas e culturais da humanidade. Entre estas, as da informação. O uso desse conjunto de conhecimento, transmitidos teórica e sistematicamente e integrados à ciência básica, define e revela o desenvolvimento e o estágio tecnológico e cultural de um país.

As tecnologias de diferentes épocas e sociedades costumam ser identificadas como termômetros do estágio cultural dessas sociedades. Nessa circunstância, (re)conhecer o desempenho (resultados e óbices) das tecnologias aplicadas à informação ganha relevância.

\section{SOBRE O CONCEITO DE TECNOLOGIA}

Na consulta à bibliografia específica é comum constatar-se o uso da expressão "tecnologia de informação" e, muitas vezes, "novas tecnologias" ou ainda "novas tecnologias de informação". Na quase totalidade do uso da expressão, os autores estão se referindo às tecnologias digitais e eletrônicas, ao uso dos computadores, dos hardwares e dos softwares e às telecomunicações.

Em seu sentido amplo, o conceito de "tecnologia" é, geralmente, entendido pelo senso comum, como sinônimo de "técnica" ou de "máquina". No entanto, muitos autores usam o termo tecnologia como algo associado a todo produto da ciência, como algo resultante do conhecimento em qualquer das áreas sob investigação científica ou empírica. Para Pirró e Longo apud Barreto (1992, p. 12), tecnologia é definida como "o conjunto de todos os conhecimentos - científicos, empíricos ou intuitivos - empregados na produção e comercialização de bens e serviços".

De acordo com Barreto (1992, p. 12), o conceito de tecnologia está associado ao de conhecimento e este é entendido como um "conjunto de informações absorvidas ou assimiladas" e que seja capaz de transformar "a estrutura cognitiva do indivíduo, do grupo ou da sociedade". Esse conjunto de conhecimentos, quando transportado para o desenvolvimento ou melhorias de produtos e serviços de uso no mercado, adquire importância econômica sob forma de patentes, produtividade, eficiência e conforto material.

Para Barreto (1992, p. 13), tecnologia

[...] não é a máquina, ou o processo de produção com suas plantas, manuais, instruções e especificações, mas, sim, os conhecimentos que geraram a máquina, o processo, a planta industrial e que permitem sua absorção, adaptação, transferência e difusão. 
Costa (1995, p. 4), por outro lado, diz que as tecnologias de informação compreendem desde "técnica e equipamentos" até os "processos necessários ao tratamento da informação".

Tecnologias de informação podem ser definidas como o conjunto de técnicas, equipamentos e vão, portanto, desde uma simples máquina manual de datilografia até aos mais avançados produtos da informática. Nos dias atuais, têm sido consideradas como a combinação de processamento eletrônico de dados e telecomunicações.

Para Dollar (1994, p. 6), "as tecnologias de informação são instrumentos poderosos que tornam o trabalho mais rápido, tal como o fizeram o telefone, a máquina de escrever elétrica $\mathrm{e}$ a máquina fotocopiadora”.

Se aceitarmos que as tecnologias são produtos do atendimento das necessidades do homem e que, portanto são, em última análise, resultado de sua cultura, as tecnologias de informação sempre existiram no tempo, acompanhando as demais tecnologias. O que ocorre é que, hoje, a informação passa a ocupar um espaço importante na produção de bens e serviços da sociedade contemporânea. A informação em ciência e tecnologia, por exemplo, ocupa lugar de destaque nas relações econômicas, provocando a proliferação de diferentes tipos de mecanismos e registros para produzir, receber, acumular, preservar e disseminar informações.

Nessa circunstância, a microfilmagem, quando citada na literatura analisada, raramente é considerada como "tecnologia de informação", e, independentemente de seu uso, não foram encontrados registros que a denominasse como "tecnologia de preservação". A literatura internacional sequer contempla, nem mesmo entre as normas técnicas nacionais formuladas por diversos países, aí incluso os EUA, a terminologia "microfilmagem para preservação". Fox registra que "[...] se você consultar as normas técnicas buscando uma definição ou uma orientação sobre aquilo que se chama 'microfilmagem para preservação', sua consulta será inútil” (FOX, 2001, p. 9).

De qualquer forma, a microfilmagem vem sendo utilizada como uma tecnologia para a preservação e acesso de documentos arquivísticos e biblioteconômicos.

\section{TECNOLOGIAS DE PRESERVAÇÃO}

As tecnologias de preservação, latu sensu, podem ser entendidas como o conjunto de conhecimentos, procedimentos e equipamentos necessários ao tratamento dos documentos, ao controle de seu ambiente de guarda, acondicionamento, reformatação e uso para a 
prorrogação da vida útil dos registros produzidos e acumulados ao longo da história, possibilitando acesso quanto à forma e/ou conteúdo.

Faz parte desse conjunto a reformatação fílmica (microfilmagem) ou digital (digitalização) de documentos, com respectivas vantagens e desvantagens.

Apesar de ser reconhecida como uma tecnologia segura e estável, a microfilmagem é aplicável somente a documentos planos ${ }^{1}$. O problema é que, hoje, arquivos e bibliotecas produzem, recebem e acumulam um amplo espectro de documentos, que vão desde imagem em movimento (filme/película, vídeo cassete, DVD), documentos sonoros (discos: 78/LP/CD - fitas: de rolo, K7) aos chamados born digital documents (documentos que foram produzidos e acumulados e só existem em formato eletrônico/digital). Além disso, o microfilme não oferece o chamado "acesso total" (acesso remoto, on line, distribuição em rede, múltiplo acesso simultâneo e variedade de derivados: fax, impressão, e-mail etc.), típico das tecnologias de informação e comunicação.

Por sua vez, a digitalização, reconhecida como uma tecnologia capaz de oferecer múltiplo acesso (simultaneamente, isto é, vários consulentes consultando ao mesmo tempo, o mesmo documento) e disseminação da informação em escala mundial, ainda tem problemas de obsolescência tecnológica (desenvolvimentos de novos hardwares e softwares, o que exige constantes atualizações), autenticidade (alto grau de vulnerabilidade, acidental e/ou intencional), problemas com direitos autorais, carência de normas e padrões internacionais, estabilidade e garantia de preservação a longo prazo (suportes com pouco tempo de durabilidade e expectativa de vida).

Em comum, tanto a microfilmagem como a digitalização dependem de rubricas orçamentárias contínuas que garantam a preservação e o acesso contínuos e em longo prazo das respectivas mídias resultantes.

De qualquer forma, para as pretensões deste artigo, a microfilmagem (convencional ou eletrônica ${ }^{2}$ ) e a digitalização são entendidas como tecnologias de preservação e acesso, uma

\footnotetext{
${ }^{1}$ Documentos planos são aqueles que têm superfície plana, geralmente, produzidos sobre papel, como impressos, manuscritos, mapas, plantas, desenhos, gravuras, cartazes, mas também, microformas, diapositivos, negativos, cópias e ampliações fotográficas.

${ }^{2} \mathrm{O}$ processo de microfilmagem eletrônica é realizado por meio de imagens digitais. Existe e está disponível em duas técnicas. Ambas as técnicas sensibilizam a imagem em filmes de gelatina com haletos de prata sobre base de poliéster. O primeiro processo foi introduzido pela Kodak Germany: consiste em converter uma imagem gerada por meios digitais (fotografia ou scanner) em luz projetada em um conjunto de espelhos e sensibilizada 
vez que são capazes de, por meio da reformatação de documentos, oferecer alternativas de durabilidade e de consulta.

O Dicionário Brasileiro de Terminologia Arquivística define microfilmagem como "produção de imagens fotográficas de um documento em formato altamente reduzido", e digitalização como "processo de conversão de um documento para o formato digital por meio de dispositivo apropriado, como um escâner” (ARQUIVO NACIONAL, 2005, p. 69/120).

A microfilmagem, tecnologia de reformatação para preservação, é definida por Fox (2001, p. 8) como “[...] o processo de reprodução em fac-símile sobre filme fotográfico, com uma redução que requer assistência ótica para leitura do conteúdo intelectual (isto é, o que está escrito ou impresso e ilustrações) de materiais arquivísticos e de bibliotecas".

Para Fox, o uso do microfilme como tecnologia de preservação de documentos de bibliotecas e arquivos oferece a possibilidade de evitar a perda de "grandes acervos de nosso patrimônio intelectual". Chamando atenção também para a economia de espaço proporcionada pelo microfilme, Fox observa ser o microfilme "especialmente útil para séries extensas de jornais e outros periódicos cujo uso não justifica o espaço de estante que requerem". Mas alerta que muitas questões preliminares devem ser respondidas pelos responsáveis por acervos em bibliotecas e arquivos antes da adoção da microfilmagem de preservação. Fox (2001, p. 7-8) adverte ainda que o sucesso no emprego dessa tecnologia "é um desafio administrativo que requer uma análise ampla e cuidadosa" a nível local, regional ou nacional.

Desde o fim da década de 1990, em estudos e pesquisas desenvolvidos no campo da preservação nos Estados Unidos, era bastante difundida a preocupação de que a escolha da tecnologia a ser adotada para a preservação dos acervos tivesse capacidade de suportar e de interagir com sistemas digitais de acesso. Essa escolha, na grande maioria das vezes, recaía sobre o microfilme, considerado seguro para a preservação e compatível com as tecnologias digitais para migração de formato.

Os esforços iniciais de reformatação para a preservação concentram-se, inteiramente, no microfilme. Nos últimos 10 anos, a atenção tem sido dirigida ao potencial que meios alternativos podem representar para propósitos de preservação. Estudos rigorosamente precisos indicam que a expectativa de vida do microfilme, de quinhentos anos ou mais, quando adequadamente preparado, armazenado e gerenciado, supera de longe qualquer outro meio em termos de longevidade e habilidade para reformatar precisamente a informação. Nenhuma outra tecnologia

em filme. O segundo processo foi introduzido pela Zeutschel: a imagem é projetada em um monitor de alta resolução (81 megapixels) e sensibilizada em filme também de prata. O processo de revelação e visualização do microfilme gerado nesses dois sistemas é idêntico ao método convencional. 
está ainda em posição de desafiar o filme como meio de preservação para a impressão de materiais de papel. Embora seja útil continuar com a avaliação de alternativas possíveis, a maioria da comunidade de preservação continua a ver no microfilme a única verdadeira alternativa de preservação de longo prazo (JONES, 2001, p. 11).

Analisando as vantagens e desvantagens da aplicação de tecnologias de preservação, entre elas a microfilmagem, Willis (2001, p. 12) afirma sobre o microfilme: "é uma solução geralmente aceitável aqui e agora para a maioria dos materiais impressos. Trata-se de uma tecnologia bem amadurecida, familiar e difundida, e com uma ampla base estabelecida. Filmes de alta qualidade criados e armazenados de acordo com normas técnicas durarão até quinhentos anos".

Reconhecendo que o microfilme apresenta dificuldades de acesso e de distribuição da informação, Willis assinala que, em relação à preservação, ainda "não há forma alguma de armazenagem digital no mercado atual que possa ser considerada de qualidades arquivísticas ${ }^{3}$, segundo a definição tradicional", mas que a necessidade de preservação poderia ser atendida por um sistema híbrido de tecnologias que combinasse microfilmagem para a preservação e tecnologia digital para acesso e transmissão da informação (WILLIS, 2001, p. 12-13).

Alguns autores referem-se a esta questão indicando que o microfilme é "um passo intermediário razoável para a obtenção de imagens digitais" e sua armazenagem em computador. Cauteloso, Waters (2001, p. 18) acredita que esse passo deverá ser dado depois de ultrapassadas algumas etapas e que, portanto, não será de uma única e rápida vez.

Orçamentos e necessidades peculiares a cada instituição devem ainda reger as decisões e escolhas específicas, presumindo que ainda em futuro próximo o sistema híbrido de tecnologias será a opção mais segura.

Aqueles que desenvolvem a tecnologia de imagem digital para utilização na preservação de bibliotecas devem ter em mente o princípio de aperfeiçoar seu poder e influência na mudança organizacional. A economia no gerenciamento e administração dos recursos de uma biblioteca, como na maioria das grandes instituições, se reflete na racionalização de escolhas, mesmo quando se trata de uma tecnologia potencialmente revolucionária. O desenvolvimento da aplicação da imagem digital deve, então, produzir resultados no tocante aos meios, custos e benefícios que facilitem e informem, em vez de distorcer e enganar, sobre tal economia (WATERS, 2001, p. 18).

\footnotetext{
${ }^{3}$ Propriedades físico-químicas dos suportes que permitem a conservação indefinida dos documentos, observadas as condições adequadas de acondicionamento, armazenamento e climatização (ARQUIVO NACIONAL, 2005, p. 141).
}

Enc. Bibli: R. Eletr. Bibliotecon. Ci. Inf., Florianópolis, n. esp., $1^{\text {o }}$ sem. 2011. ISSNe 1518-2924. 
Pode-se interpretar essa firmação como uma advertência de que nenhuma tecnologia em si e por si resolve isoladamente problemas na área de preservação. A cautela e a adoção de critérios rigorosos baseados em boas aferições e diagnósticos podem ser fundamentais para a boa escolha tecnológica.

Fazendo referência às normas técnicas nacionais (Estado Unidos) que apontam benefícios e características únicas para a tecnologia de microfilmagem para preservação, Fox reforça o uso do microfilme como diferenciada tecnologia de preservação:

O propósito primário da microfilmagem para preservação é proporcionar substituição para materiais escritos ou impressos sobre papel de baixa qualidade, mais provavelmente que já tenham se tornado quebradiços, de forma que os conteúdos continuarão, para sempre, disponíveis à comunidade de estudiosos e de pesquisa. $\mathrm{O}$ que distingue a microfilmagem para preservação como um subconjunto especial da microfilmagem de fontes documentais é a intenção de se criar uma substituição permanente, um meio arquivístico (FOX, 2001, p. 9).

Yola De Lusenet, por sua vez, concorda que, do ponto de vista da preservação, a escolha opõe o microfilme, uma tecnologia confiável e de uso comprovado, à digitalização, uma tecnologia nova que oferece muitas possibilidades, mas grandes riscos. Mesmo em relação ao dito "sistema híbrido" (que combina as vantagens de ambas as tecnologias), Lusenet não demonstra entusiasmo. Para a autora, citando Graham Jefcoate, o uso combinado de microfilmagem para preservação e digitalização para o acesso, também já começou a ruir. O problema é que

[...] como a digitalização não é direcionada essencialmente para a preservação, a preservação dos originais ameaça se tornar uma preocupação subsidiária. O que é digitalizado provavelmente será preservado, mas o que precisa ser preservado só será selecionado para digitalização se houver argumentos fortes para o seu uso. É possível afirmar seguramente que somente uma fração do que está disponível em bibliotecas e arquivos será digitalizada em um futuro próximo. Acervos com baixa frequência de uso ou aqueles que contêm materiais que interessam, principalmente, a especialistas não estarão entre os primeiros candidatos. E se estiverem em risco, medidas complementares ainda terão que ser tomadas para a sua sobrevivência (LUSENET, 2003, p. 112 - tradução nossa).

Baseando-se no argumento muito difundido pelos que defendem a digitalização (de que as amplas possibilidades de acesso por meio da imagem digital seria uma vantagem inegável), Lusenet chama a atenção para alguns cuidados a serem tomados nesse sentido, quando salienta que a questão da quantidade de acesso não deve ser confundida com a qualidade do acesso.

[...] o que preocupa na discussão sobre as vantagens das imagens digitais é que o acesso [uso] é entendido frequentemente como um conceito quantitativo, apenas. Mas se nós considerarmos o acesso apenas como dado numérico, pode-se camuflar a complexidade que há por trás de simples linhas ascendentes do número de usuários 
em um gráfico. A digitalização é a grande favorita entre políticos e os que decidem porque quanto mais coleções estiverem disponíveis, mais pessoas as poderão usar. Até aqui tudo bem. Mas há uso e uso. Entre os que acessam um site há muitos usuários casuais. $\mathrm{O}$ que significa se 10.000 pessoas visitarem um site? Como nós interpretamos estatísticas de usuário para avaliar o impacto da digitalização? Se tudo o que possamos medir com certeza for frequência de uso, há um risco de que o aumento de usuários se torne a medida de sucesso, independentemente do em que esse uso consiste e de quem são os usuários. Isso favorece a seleção de coisas que são de algum interesse para um grande número de pessoas, sobre coisas que são de extrema importância a apenas alguns - pesquisadores, por exemplo, que dependem desses materiais para o seu trabalho. É necessário um conceito sofisticado de acesso [uso] e uma compreensão profunda dos grupos-alvo [de usuários] para superar a pressão dos números e o risco de se promover um acesso trivial, a custa de um acesso mais sério (LUSENET, 2003, p. 113 - grifos do autor - tradução nossa).

\begin{abstract}
Além disso, outro aspecto salientado por Lusenet, que requer atenção, são os requisitos de qualidade técnicos para a produção de cópias matrizes, de substituição ou consulta.
\end{abstract}

\begin{abstract}
O objetivo de um projeto de digitalização deve determinar requisitos de qualidade e manutenção, mas os requisitos para as matrizes digitais de preservação, que venham a desempenhar o papel de cópias de substituição, devem ser diferentes dos requisitos para a produção de cópias de usuário. Os requisitos para as matrizes digitais de preservação não conseguirão ser atendidos se a motivação real para digitalização é facilitar a utilização, pois, na verdade, produzir matrizes digitais de preservação, que deverão ser mantidas ao longo do tempo, de originais que não estão em risco ou que já tenham sido microfilmados, acabará sendo uma decisão antieconômica (LUSENET, 2003, p. 114 - tradução nossa).
\end{abstract}

Ou seja, na visão da autora, os custos financeiros que o atendimento de requisitos tecnológicos e de controle de qualidade na reformatação de documentos apenas para facilitar o seu acesso e uso seriam de tal monta que praticamente inviabilizariam a sua execução.

Complementar a isso, há problemas típicos e da própria natureza da tecnologia que não apenas dificultam a superação dos entraves no uso da digitalização para a preservação, como, novamente, encarecem os projetos, em vista de exigências incontornáveis para a manutenção minimamente satisfatória da tecnologia utilizada. Sobre isso, Lusenet alerta para um dos maiores perigos da imagem digital para preservação: a constante necessidade de atualização de um formato que pouco tem de tangível, se comparado ao microfilme.

[...] mantê-la acessível requer um processo contínuo e intenso de atualização e conversão, com risco de algo correr mal a cada passo. Os carriers em que ele é armazenado podem se degradar rapidamente e as máquinas e os programas para acessar as informações se tornam desatualizados em poucos anos. Não há um processo lento de degradação ou algo que vá comendo pelas beiradas, não, um dia você descobre que simplesmente tudo se perdeu ou que as informações ainda podem estar lá, mas estão bloqueadas por códigos e você não consegue acessá-las - como um náufrago faminto em uma ilha deserta com uma lata de feijão, mas sem um abridor de latas. (...) Em suma, embora matrizes digitais, na prática, sejam e serão criadas e preservadas, do ponto de vista da preservação, a digitalização é ainda uma abordagem de alto risco. No fim das contas, você tenta resolver um problema de 
preservação, salvando a informação de um documento original, substituindo-o por um outro documento, mais complexo (LUSENET, 2003, p. 114 - tradução nossa).

Um último elemento tratado por Lusenet corrobora mais um dos aspectos levantados neste artigo: a importância de se conhecer os custos financeiros no planejamento de preservação. Para Lusenet, não há ainda suficiente experiência prática na manutenção de longo prazo dos materiais digitais para se ter certeza sobre alguma coisa e, muito menos, sobre custos financeiros. Lusenet trata da questão dos custos de armazenagem recorrendo a um artigo de Chapman, publicado em 2004, onde este compara o custo de armazenar a mesma quantidade de informações em formato analógico no Depósito Central de Harvard e em formato digital no Arquivo Digital da OCLC (Online Computer Library Center Digital Archive). Chapman apresenta números para os custos relativos de armazenar 729.000 páginas de texto $(2.202$ volumes), em formato de livro e em microfilmes, armazenados em câmaras de segurança ${ }^{4}$ (vault, em Inglês) ou em salas com controle ambiental, do Harvard Depository, com imagens de página de 1 bit e em ASCII $^{5}$ no OCLC Digital Archive. O estudo indica que o armazenamento em ASCII é a opção mais barata, pois este é um formato extremamente compacto.

No entanto, é um formato que só pode ser utilizado se a aparência do texto (o layout de página) não for importante e se não houver ilustrações. $\mathrm{O}$ armazenamento de microfilmes vem em segundo lugar como opção mais barata, no entanto, se os microfilmes forem mantidos em câmaras de segurança, os custos duplicam. Em terceiro lugar, vem o armazenamento em formato de livro, e em quarto, o armazenamento como imagens de página de 1 bit. Mesmo a uma taxa mais baixa (para uma conta de mais de $1.000 \mathrm{~GB}$ ), o armazenamento de imagens digitais é 1,5 vez mais caro que o armazenamento de livros e 2,5 vezes mais caro que o armazenamento de microfilme em câmara de segurança. A compactação sem perda foi utilizada para os arquivos digitais; se descompactados, os arquivos iriam se tornar 22 vezes maiores e armazená-los ficaria 54 vezes mais caro do que armazenar o mesmo número de páginas em microfilme na câmara de segurança. Chapman também compara os custos de armazenamento de cópias de microfilmes com vários formatos digitais. Como os custos estão diretamente relacionados com o número de gigabytes exigido para armazenamento, o

\footnotetext{
${ }^{4}$ Local próprio para armazenamento dotado de condições especiais visando restringir o acesso e garantir a máxima segurança contra furtos e sinistros (ARQUIVO NACIONAL, 2005, p. 43).

${ }^{5}$ American Standard Code for Information Interchange, em português, Código Padrão Americano para o Intercâmbio de Informação.
} 
tamanho do arquivo é um fator decisivo, sendo que o tamanho do arquivo é determinado pela qualidade escolhida para reformatação: bitonal ou 1 bit; cinza ou 8 bits; colorido ou 24 bits. O efeito sobre os custos de armazenar matrizes de alta qualidade é muito claro no estudo feito por Chapman: armazenar as mesmas páginas com imagens de 8 bits em vez de 1 bit é cerca de 42 vezes mais caro; as imagens de 24-bit têm custo de cerca de 125 vezes mais se comparadas com imagens de 8-bits. Convém ter em mente que em muitos casos os custos de armazenar arquivos digitais ou microfilmes, ou mesmo usando o sistema híbrido, se somarão aos custos de armazenamento de material impresso, por que muitas instituições mantêm os originais após a microfilmagem ou a digitalização. E se, para limitar os riscos, são mantidas várias cópias do microfilme ou dos arquivos digitais, isso também aumenta os custos. (LUSENET, 2003, p. 116 - tradução nossa).

Lusenet conclui dizendo que

[...] a escolha da tecnologia e de seus requisitos de qualidade mudam de acordo com as metas que se quer alcançar. A preservação da informação é distinta da preservação do uso dessa informação, e as tecnologias [microfilmagem para a preservação e a digitalização para o acesso] devem ser vistas como complementares. Os requisitos de usuários e os requisitos para a preservação nem sempre são alcançados com a mesma tecnologia. Uma tecnologia estabelecida como o microfilme ainda tem um papel a cumprir numa política de gestão de acervos que busque equilibrar diferentes requisitos e não apenas adotar o 'tamanho único' como solução para tudo (LUSENET, 2003, p. 117 - tradução nossa).

Algumas instituições de relevo internacional na área não deixam dúvidas sobre o papel que o microfilme ainda tem a cumprir e podem oferecer um testemunho atualizado sobre a questão.

Em seu site, o NARA - The United States National Archives and Records Administration questiona: "Na era da digitalização, por que o NARA continua a microfilmar documentos?" (In an era of digitization, why NARA continue to microfilm records?) para logo a seguir afirmar:

O microfilme é um meio de armazenagem padronizado de imagens a longo prazo, de baixo custo e seguro. $\mathrm{O}$ equipamento necessário para a leitura de imagens de microfilmes é simples, pois consiste em luz e ampliação. O microfilme tem uma expectativa de vida de centenas de anos.

As imagens digitais, por outro lado, implicam em uma ampla variedade de códigos, que requerem hardwares e softwares para as tornarem legíveis. Além disso, para evitar a obsolescência causada pelas alterações na tecnologia dos computadores, as imagens digitais têm de ser periodicamente reformatadas. O custo de manutenção do microfilme é pequeno se comparado com o das imagens digitais. O microfilme só precisa ser armazenado em um lugar fresco e seco para durar um longo período de tempo. O NARA microfilma apenas aqueles documentos que, por serem frequentemente utilizados, tem maior risco de se deteriorarem. A maioria dos documentos não é usada com uma frequência que justifique a sua microfilmagem. $O$ NARA já microfilmou milhões de páginas de documentos permanentes do governo 
federal, mas sabe que as imagens digitais facilitam o acesso e a transferência de documentos. Por isso, trata de se manter em dia com a tecnologia digital, inclusive aplicando-a experimentalmente, como pode ser visto em um banco de dados protótipo (NARA's ARC - Archival Research Catalog - A Prototype Database of Selected Holdings) (UNITED STATES NATIONAL ARCHIVES AND RECORDS ADMINISTRATION - tradução nossa).

Sobre os documentos arquivísticos ditos especiais ${ }^{6}$, o NARA indica a reformatação e duplicação para preservação, o que está sob responsabilidade de seu Laboratório de Preservação de Documentos Especiais (Special Media Preservation Laboratory):

O Laboratório de Preservação de Documentos Especiais é responsável por reformatar e duplicar documentos textuais e não textuais. Isso inclui duplicar filmes de imagens em movimento, fotografias, microfilmes e fitas áudio e vídeo; microfilmagem de documentos em papel; reformatar áudio e vídeo gravados em formatos obsoletos que já não podem ser usados nos equipamentos atuais, e gerando imagens digitais de documentos. Esse conjunto de ações resulta na retirada de documentos frágeis do uso, ao mesmo tempo em que providencia acesso ao seu conteúdo informacional com a captura da informação em um novo formato (UNITED STATES NATIONAL ARCHIVES AND RECORDS ADMINISTRATION (USA) - tradução nossa).

Apesar de não estar explícito, é possível deduzir-se da citação acima que filmes, fotografias, microfilmes e fitas de áudio e vídeo sob custódia do NARA são apenas duplicados para a sua preservação e reformatados somente quando não existem mais os equipamentos necessários para sua leitura e audição. Ou seja, a duplicação utiliza a mesma tecnologia e suporte que a matriz original (com as devidas adaptações e respeito à evolução tecnológica, produz nova fita magnética de áudio e vídeo a partir da original, por exemplo), e a reformatação muda o formato suporte do documento original (do papel para microfilme; do papel para imagem digital; da fita magnética de áudio e vídeo para mídia digital etc. $)^{7}$.

A Universidade de Harvard (USA) também apresenta algumas constatações interessantes sobre a questão, no documento intitulado "Resultados preliminares de investigação para melhorar microfilmes para serem digitalizados" (Preliminary Results of Investigation to Optimize Microfilm for Digitization).

O relatório apresenta resultados preliminares sobre modificações nos procedimentos de microfilmagem para preservação. A investigação procurou saber se a reformatação de livros

\footnotetext{
6“'Documento em linguagem não textual, em suporte não convencional, ou, no caso de papel, em formato e dimensões excepcionais, que exigem procedimentos específicos para seu processamento técnico, guarda e preservação, e cujo acesso depende, na maioria das vezes, de intermediação tecnológica" (ARQUIVO NACIONAL, 2005, p. 75).

${ }^{7}$ Não foi identificada qualquer menção ou registro no site do NARA sobre reformatação / digitalização de documentos arquivísticos especiais como estratégia de preservação.
}

Enc. Bibli: R. Eletr. Bibliotecon. Ci. Inf., Florianópolis, n. esp., $1^{\circ}$ sem. 2011. ISSNe 1518-2924. 
quebradiços $^{8}$, usando o sistema híbrido de microfilmar-primeiro/digitalizar-depois ${ }^{9}$, poderia resultar em uma melhor imagem digital do material deteriorado. Isto é, tratou-se de saber se o aperfeiçoamento do microfilme resultaria na melhoria da qualidade da imagem dos documentos e se os custos diminuiriam com a digitalização. Em relação aos custos, uma das questões era saber em quanto aumentaria o custo da microfilmagem com a adoção de modificações que melhorassem a imagem digital resultante. Algumas observações foram apontadas:

[...] criar metadados estruturais a partir de cópias (microfilme), embora eficaz em termos de custos, é propenso a erro; a atenção no momento de microfilmar, bem como a inclusão de dados técnicos no começo de cada rolo [sinaléticas], produzirá uma digitalização de qualidade superior; as informações registradas nos relatórios de controle de qualidade do microfilme são fundamentais para a checagem, inspeção e outros processos da digitalização e de seus metadados estruturais (HARVARD, 2007 - tradução nossa).

Mais do que os resultados (preliminares) em si da investigação, interessa aqui chamar atenção para a preocupação da Universidade de Harvard em levantar e obter dados confiáveis, a partir de estudos sistemáticos e metodológicos, para subsidiar as escolhas e decisões políticas e tecnológicas em relação às tecnologias para preservação e acesso de documentos de arquivos e bibliotecas.

A Biblioteca Britânica, por sua vez, produziu o que chama de Position Paper sobre sua Política de Cópias para Preservação - do microfilme ao digital (Preservation Copying Policy - microfilm to digital / Colletion Care 2008) para o período de 2008 a 2012, onde é enfática ao afirmar:

\begin{abstract}
A preferência atual da Biblioteca Britânica para a cópia de preservação é o microfilme, cuja longevidade (quando as normas são respeitadas) é largamente reconhecida pela comunidade que trata de Patrimônio, bem como preenche completamente os requisitos de uma preservação de longo prazo. A Biblioteca Britânica não considera, hoje, a produção de cópias digitais como uma estratégia universal de preservação (BRITISH LIBRARY (UK), 2008 - tradução nossa).
\end{abstract}

Logo após listar uma série de fatores a serem alcançados para que a Biblioteca Britânica mude do microfilme para a digitalização (como “A existência comprovada de preservação do

\footnotetext{
${ }^{8}$ São os livros impressos em papel moderno que, pela combinação de fatores intrínsecos (manufatura e industrialização do papel) com fatores extrínsecos (temperatura e umidade no ambiente de guarda), sofrem uma acelerada decomposição ácida que resulta no rompimento da estrutura químico-física do papel. São os chamados "papéis ácidos".

${ }^{9}$ Procedimento típico do "sistema híbrido", quando o documento original é primeiramente microfilmado para, depois, digitalizar o microfilme produzido.
}

Enc. Bibli: R. Eletr. Bibliotecon. Ci. Inf., Florianópolis, n. esp., 1º sem. 2011. ISSNe 1518-2924. 
digital" ou "A existência de padrões internacionais para a produção de substitutos digitais"), o documento registra que:

As vantagens da cópia digital para o acesso são significativas, assim como os potenciais benefícios para os serviços de consulta. Entretanto, como responsável pela custódia de uma importante coleção patrimonial, é vital para Biblioteca Britânica que qualquer alternativa proposta, em relação à preservação e ao acesso de longo prazo, tenha sido comprovada (BRITISH LIBRARY (UK), 2008 - grifo nosso - tradução nossa).

E é exatamente por isso que o tal Position Paper informa que a Biblioteca Britânica optou pela estratégia de desenvolver um projeto provisório de escanear e microfilmar que “possibilitará que o processo de cópia digital para preservação se desenvolva concomitantemente com as já existentes e comprovadas práticas de cópias para preservação" (BRITISH LIBRARY (UK), 2008 - tradução nossa).

Nesse sentido, a Biblioteca Britânica apresenta dois aspectos de sua política de cópias para preservação: a posição atual (em 2008) e os aspectos que estão sendo amadurecidos. Entre outros, destacam-se:

Posição atual (2008)

- A microfilmagem com qualidade arquivística é hoje o formato escolhido para a preservação;

- O microfilme é visto primeiramente como um meio de preservação, com possibilidades de acesso;

- A digitalização é vista primeiramente como um meio de acesso, com possibilidades potenciais de preservação, mas não é considerada como uma ferramenta de preservação per se;

- Exceções, no momento, são feitas para os documentos sonoros analógicos e para a captura e reprodução fiel de fotografias coloridas esmaecidas (BRITISH LIBRARY (UK), 2008 - grifo nosso - tradução nossa).

Entre os aspectos que estão sendo amadurecidos (Maturing factors), o documento da Biblioteca Britânica chama atenção quando menciona que algumas projeções indicam que "enquanto a microfilmagem convencional e seus equipamentos entram em declínio, um novo mercado de microfilmes - o microfilme digital de preservação (microfilm digital preservation) emergirá, usando o microfilme como uma parte integral da preservação digital" (BRITISH LIBRARY (UK), 2008 - tradução nossa) ${ }^{10}$.

Em relação ao Brasil, mesmo com três décadas de uso de tecnologias para preservação em arquivos e bibliotecas ${ }^{11}$, não foram localizados qualquer estudo ou relatório com análises

\footnotetext{
${ }^{10}$ Aparentemente, o documento da Biblioteca Britânica está se referindo à microfilmagem eletrônica.

${ }^{11} \mathrm{Na}$ década de 1970, a microfilmagem se impôs como a tecnologia preferencial. Na década de 1990, a digitalização surge como uma alternativa excludente, em relação à microfilmagem, na preservação e acesso aos

Enc. Bibli: R. Eletr. Bibliotecon. Ci. Inf., Florianópolis, n. esp., $1^{\text { }}$ sem. 2011. ISSNe 1518-2924. 
qualitativas e/ou quantitativas sobre vantagens e desvantagens no uso da microfilmagem e da digitalização em arquivos e bibliotecas.

\section{CONSIDERAÇÕES FINAIS}

Ao contrário do que se poderia pensar, em um primeiro momento, a microfilmagem não deve ser considerada como uma tecnologia em declínio e nem mesmo com tendência de desuso. Verificou-se que autores e instituições públicas e privadas dos países centrais, quando se defrontam com a questão da microfilmagem, são praticamente unânimes em afirmar que ela ainda é insubstituível como tecnologia para preservação de documentos planos. De uma maneira geral, pode-se afirmar que há uma tendência entre os estudiosos do problema de aceitar que o vínculo da microfilmagem com a digitalização pode ser benéfico e bem-vindo. No entanto, esses mesmo autores são praticamente hegemônicos ao dizer que a digitalização ainda não reúne as condições tecnológicas e financeiras mínimas necessárias para ser aceita como uma tecnologia de preservação segura e eficaz.

Isso decorre, basicamente, da combinação de dois fatores: o relativo pouco tempo e estudos sobre o uso, vantagens e desvantagens da tecnologia digital, e a natureza dinâmica da tecnologia digital, que faz com que a velocidade da evolução de softwares e hardwares dificulte, tecnológica e financeiramente, a atualização necessária para o seu uso seguro a longo prazo. Relatos de experiências e estudos internacionais têm demonstrado que o abandono das tecnologias tradicionais de preservação (como a microfilmagem, a duplicação e a conservação preventiva) em favor do uso exclusivo da tecnologia digital para preservação e acesso não tem sido uma boa escolha. Do ponto de vista das decisões políticas, raros são os gestores que a adotam sem temores e cuidados. Nem mesmo do ponto de vista orçamentário e financeiro, a sua adoção é vista como eficaz. Ainda que, em um primeiro momento, as tecnologias digitais tenham retirado algum recurso da preservação convencional, hoje, raros

documentos para, em meados da mesma década, começar a ser substituído pelo chamado sistema híbrido. Incontornável, no caso do Brasil, é o estudo do Plano Nacional de Microfilmagem de Periódicos Brasileiros. O PLANO pode ser considerado como o mais sólido e duradouro projeto de microfilmagem desenvolvido no Brasil. O PLANO tem origem no Departamento de Assuntos Culturais (DAC) do MEC e surge "nos termos dos objetivos da Política Nacional de Cultura (PNC), dentro do Plano Setorial da Educação e Cultura do MEC" para ser "integrado ao Programa Nacional de Preservação da Documentação de interesse histórico-cultural" (Pró-Documento), conforme está estabelecido no item I da portaria n. ${ }^{\circ} 31$, de 11 de dezembro de 1978 , que cria o PLANO. Quatro anos depois, com a portaria n. ${ }^{\circ} 23$, de 26 de outubro de 1982, que modifica o PLANO, sua subordinação passa para a Secretaria de Cultura do MEC, sob a supervisão da Fundação Nacional Pró-Memória e em cujo orçamento fica contemplada, de acordo com o estabelecido no item I e no item VI da referida portaria.

Enc. Bibli: R. Eletr. Bibliotecon. Ci. Inf., Florianópolis, n. esp., $1^{\text {o }}$ sem. 2011. ISSNe 1518-2924. 
são os arquivos e bibliotecas que, ao adotar a microfilmagem e a digitalização, não municiam rubricas orçamentárias para ambas as tecnologias, duplicando custos.

Portanto, mais do que sugerir ou indicar procedimentos técnicos que possam nortear a escolha por uma ou outra tecnologia de informação, é preciso levantar dados, torná-los confiáveis e consolidá-los minimamente, analisá-los e apresentá-los de tal forma que possam municiar aqueles que tenham responsabilidade institucional de planejar e escolher as tecnologias de informação a serem adquiridas, mantidas e utilizadas com dinheiro público.

Nesses termos, o que importa saber?

Para ampliar e aprofundar o conhecimento de elementos que compõem o problema e, assim, revelar aspectos desconhecidos ou obscuros desse problema, é necessário o recolhimento e a análise de dados de um modo minimamente sistemático. Nesse sentido, está sendo desenvolvido um projeto de pesquisa no âmbito do qual foi construído e começa a ser testado em algumas instituições públicas brasileiras que recorreram à microfilmagem de acervos arquivísticos entre 1979 e 2008, um "modelo descritivo" para sistematizar o trabalho de levantamentos de dados e a subsequente análise a ser desenvolvida ${ }^{12}$. O mesmo modelo pode ser testado também em relação à digitalização, concomitantemente à microfilmagem ou não. Nesse modelo, estão articulados, de forma operacional, a tecnologia em estudo (no caso, a microfilmagem); duas dimensões dessa tecnologia (preservação e acesso); três componentes que aparecem nesse fazer (recursos humanos, recursos tecnológicos e recursos financeiros); aos quais estão vinculados diversos indicadores (listados a seguir).

Em relação aos recursos humanos: levantamento da quantidade e a qualidade dos recursos humanos empregados na microfilmagem, identificando a qualificação/titulação, o vínculo empregatício (estável ou terceirizado), cursos de aperfeiçoamento feitos, tempo de serviço e a quantidade de técnicos utilizados no período estudado.

Em relação aos recursos tecnológicos: levantamento da quantidade e a qualidade dos recursos tecnológicos empregados na microfilmagem, identificando os tipos e modelos de equipamentos, a manutenção e a atualização dos equipamentos, a quantidade e a qualidade dos produtos obtidos (rolos de microfilmes), a quantidade e a qualidade da preservação (estado de conservação e de armazenagem) desses produtos e a quantidade (números de consultas / usuários) e a qualidade (grau de satisfação do usuário) do acesso.

\footnotetext{
${ }^{12}$ Modelo construído a partir de Quivy e Campenhoudt (2003).
} 
Em relação aos recursos financeiros: levantamento dos recursos orçamentários destinados à microfilmagem em relação aos recursos humanos e tecnológicos empregados, identificando o valor absoluto investido (soma de todos os recursos públicos e privados aplicados); o custo relativo de cada mídia produzida (relação entre o custo da matéria-prima + o custo da mão de obra + o custo dos equipamentos dividido pelo número de rolos produzidos).

O quadro abaixo ilustra, em síntese e esquematicamente, as relações entre tecnologias, dimensões, componentes e indicadores desenhados para a pesquisa.

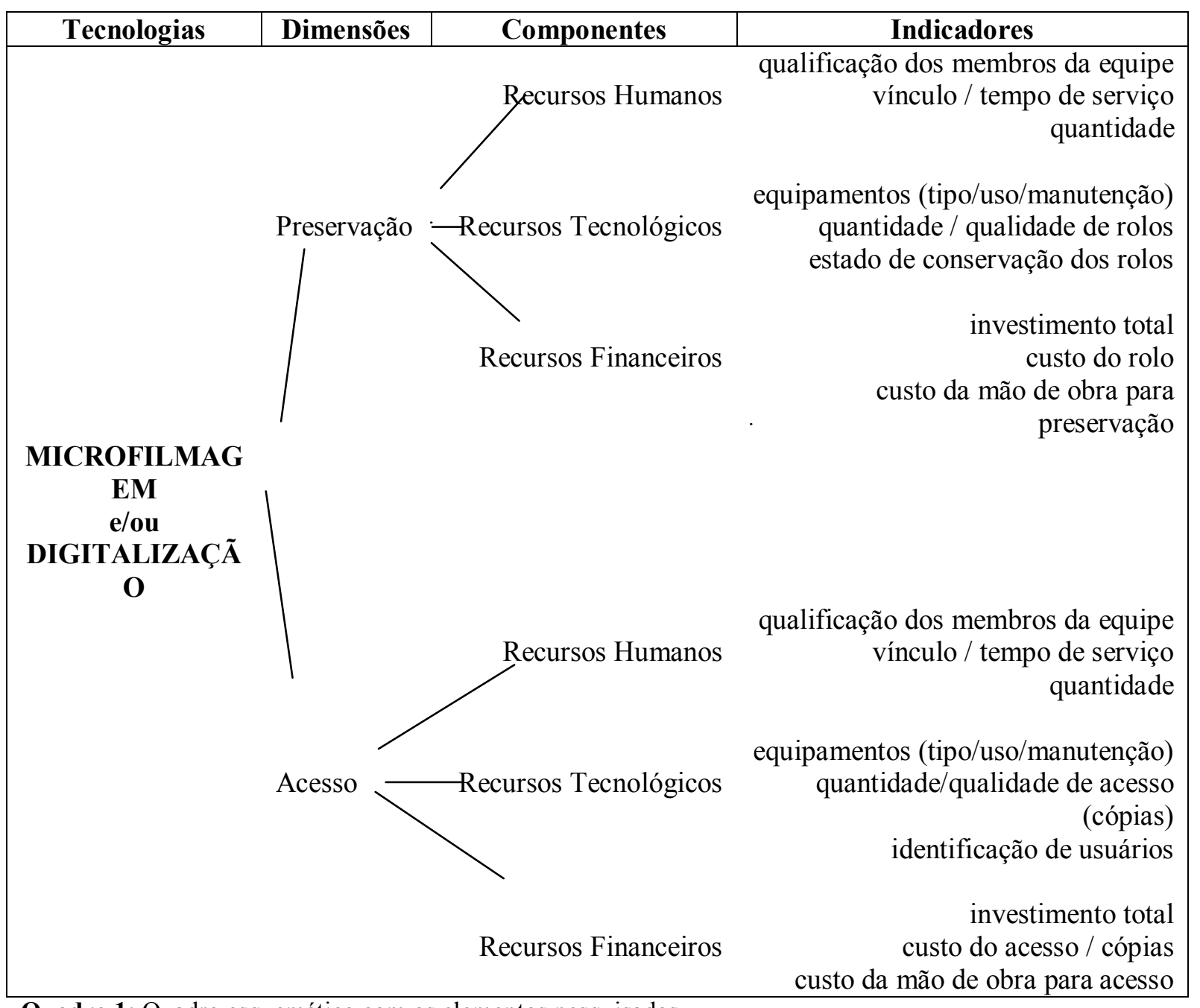

Quadro 1: Quadro esquemático com os elementos pesquisados

Fonte: $\mathrm{O}$ autor

Em síntese, espera-se que tal levantamento retrospectivo, metodologicamente construído, tendo como objeto de análise a trajetória de anos no uso da microfilmagem no Brasil, contribua com o conhecimento em que se baseiam os dirigentes de instituições na formulação de seus planejamentos em relação ao uso das tecnologias para preservação e acesso de documentos sob sua custódia. Em outras palavras, que a opção por esta ou aquela tecnologia Enc. Bibli: R. Eletr. Bibliotecon. Ci. Inf., Florianópolis, n. esp., $1^{\text {o }}$ sem. 2011. ISSNe 1518-2924. 
de informação para a preservação e acesso possa se basear em dados estatísticos e projeções analíticas sobre o assunto. Entende-se que, dessa forma, seja possível oferecer subsídios para futuras escolhas políticas e decisões estratégicas, que analisem o uso da microfilmagem e da digitalização como tecnologias para a preservação e acesso de documentos.

\section{REFERÊNCIAS}

ARQUIVO NACIONAL (Brasil). Dicionário brasileiro de terminologia arquivística. Rio de Janeiro: Arquivo Nacional, 2005.

BARRETO, Aldo de Albuquerque. Informação e transferência de tecnologia: mecanismos de absorção de novas tecnologias. Brasília: IBICT, 1992.

BRITISH LIBRARY (UK). Preservation Copying Policy (Microfilm to digital). Position

Paper. Collection Care 2008. Disponível em:
$<$ http://www.bl.uk/aboutus/stratpolprog/ccare/introduction/preservation/policy\&position/Posit ion\%20Paper-Preservation\%20Copying\%20Policy.pdf>. Acesso em: 22 jul. 2010.

CHAPMAN, Stephen. Counting the costs of digital preservation: is repository storage affordable? Journal of Digital Information. v. 4, n. 2, May 2004. Disponível em: $<$ http://journals.tdl.org/jodi/article/view/100/99>. Acesso em: 20 jul. 2010.

CONWAY, Paul. Preservação no universo digital. Rio de Janeiro: Projeto Conservação Preventiva em Bibliotecas e Arquivos, Arquivo Nacional, 2001.

COSTA, Sely Maria de Souza. Impactos sociais das tecnologias de informação. Revista Bibliotecon. Brasília, v. 19, n. 1, jan./jun. 1995. p. 3-22.

DOLLAR, Charles. O Impacto das tecnologias de informação sobre princípios e práticas de arquivos: algumas considerações. Acervo. Rio de Janeiro, v. 7, n. 1-2, jan./dez., 1994. p.3-38.

Tecnologias da Informação Digitalizada e Pesquisa Acadêmica nas Ciências Sociais

e Humanas: o papel crucial da arquivologia. Estudos Históricos, Rio de Janeiro, 1994. v. 7, n. 13 , p. $65-70$.

ENGELS, Friedrich. A Origem da família, da propriedade privada e do estado. Rio de Janeiro: Civilização Brasileira, 1975.

FOX Lisa L. Microfilmagem de preservação. Rio de Janeiro: Projeto Conservação Preventiva em Bibliotecas e Arquivos, Arquivo Nacional, 2001.

HARVARD UNIVERSITY (USA). Library Preservation at Harvard. Preliminary results of investigation to optimize microfilm for digitization. 2007 by the President and Fellows of Harvard College. Disponível em: $<\mathrm{http}: / /$ preserve.harvard.edu/pubs/microfilm_for_digitization.pdf $>$. Acesso em: 20 jul. 2010.

HOOVER INSTITUTE LIBRARY AND ARCHIVES. Microfilm preservation in a digital world. All documents accessed March 18, 2004. Disponível em: $<$ http://0055d26.netsolhost.com/hila/preservation.htm>. Acesso em: 26 jun. 2009.

JARDIM, José Maria. As Novas Tecnologias da Informação e o Futuro dos Arquivos. Estudos Históricos, Rio de Janeiro, v. 5, n. 10, 1992. p. 251-260. 
JONES, Lee C. Microfilme para preservação: plataforma para sistemas digitais de acesso. Rio de Janeiro: Projeto Conservação Preventiva em Bibliotecas e Arquivos, Arquivo Nacional, 2001.

LUSENET, Yola de. Microfilm and digitization as choices in preservation. LIBER Quarterly (The European Commission on Preservation and Access - ECPA), v. 13 (2003), n. 2. K.G. Saur, Munich, Printed in Germany. Disponível em: $<$ http://liber.library.uu.nl/publish/articles/000016/article.pdf $>$. Acesso em: 19 jul. 2010.

SILVA, Sérgio Conde de Albite. A preservação da informação arquivística governamental nas políticas públicas do Brasil. Rio de Janeiro: AAB/FAPERJ, 2008.

SILVA, Sérgio Conde de Albite. Políticas públicas de preservação e tecnologias de informação: o Plano Nacional de Microfilmagem de Periódicos Brasileiros. Rio de Janeiro: UNIRIO, 1988. Dissertação (Mestrado em Memória Social e Documento) - UNIRIO, 1998.

UNITED STATES NATIONAL ARCHIVES AND RECORDS ADMINISTRATION NARA. In an era of digitization, why does NARA continue to microfilm records? Disponível em: <http://www.archives.gov/preservation/formats/microfilming.html $>$. Acesso em: 21 jul. 2010.

WATERS, Donald J. Do microfilme à imagem digital. Rio de Janeiro: Projeto Conservação Preventiva em Bibliotecas e Arquivos, Arquivo Nacional, 2001.

WILLIS, Don. Uma abordagem de sistemas híbridos para preservação de materiais impressos. Rio de Janeiro: Projeto Conservação Preventiva em Bibliotecas e Arquivos, Arquivo Nacional, 2001.

\begin{abstract}
Analyzes the use of digitization and microfilming for preservation and access to documents in archives. Presents as some international institutions in the area are dealing with the issue. Points out that the choice of one or another technology for preservation and access must be based on statistical data and retrospective studies obtained in experiments. To know and to measure, quantitative and qualitatively, the human resources, technological and financial into microfilming and digitization of collections for preservation and access in archival institutions, mainly, the public, provides a foundation for future projects.
\end{abstract}

Keywords: Microfilming. Digitization. Preservation. Access. Archives.

Originais recebidos em: 03/10/2010

Aceito para publicação em: 15/12/2010 